\title{
ESTUDIOS
}

\section{Liderazgos, no líderes. Los Ejercicios Espirituales y las escuelas de negocios}

\author{
Josep M. Lozano'
}

Resumen: La pregunta última que se plantea este artículo es si hay algo que distingue o diferencia a una Jesuit Business School (JBS) de otras escuelas de negocios. El abordaje de la cuestión se hace a través de una temática que en los últimos años ha cobrado especial relevancia por su impacto social y por su transversalidad educativa: el liderazgo. La pregunta, pues, se concreta en explorar cómo cabe entender el liderazgo y si es posible una aproximación específica al liderazgo (especialmente desde el punto de vista educativo) en el marco de una JBS. En la primera mitad del paper se propone una comprensión de la temática que aborda el liderazgo y un enfoque de la misma. En la segunda mitad, a partir de una relectura antropológica de algunas meditaciones de los Ejercicios Espirituales, se propone un marco de referencia para el tratamiento del liderazgo en una JBS.

Palabras clave: liderazgo, espiritualidad ignaciana, escuelas de negocios.

Fecha de recepción: 20 de enero de $201 \mathrm{I}$.

Fecha de aceptación definitiva: 15 de junio de $201 \mathrm{I}$.

\section{Leadership, not Leaders. Spiritual Exercises and business schools \\ Leaderships, leaders non. Les Exercices Spirituels et les écoles de commerce}

Abstract: The final question that arises in this paper is whether there is something that differentiates a Jesuit Business School (JBS)
Résumé: La question ultime que pose cet article est de savoir s'il y a quelque chose

' ESADE (Universidad Ramon Llull), Barcelona. 
from other business schools. This question is addressed through a tendency that has become especially relevant in the recentyears due to its social impact and its educational transversality: leadership. The question, then, is to explore what is meant by leadership and if it is possible to define it (especially from an educational point of view) within the framework of a JBS. The first half of this paper proposes an understanding of the issues encompassing leadership and an approach to it. The second half, based on an anthropological rereading of some meditations in the Spiritual Exercises, proposes a framework for dealing with leadership in a JBS

Key words: Leadership, Ignatian spirituality, business schools. qui distingue ou qui représente une différence entre une Jesuit Business School (JBS) et une autre école de commerce. L'abord de cette question se fait à travers une thématique qui, lors des dernières années, a pris une importance particulière dû à son impact social et à sa transversalité éducative: le leadership. La question se concrétise donc dans le fait $d^{\prime}$ explorer comment on doit comprendre le leadership et s'il est possible de s'en approcher d'un point de vue spécifique (spécialement du point de vue éducatif) dans le cadre d'une JBS. Dans la première moitié de l'article nous proposons une compréhension de la thématique abordée sur le leadership et une approche de celle-ci. Dans la deuxième moitié, à partir d'une relecture anthropologique de quelques méditations des Exercices Spirituels, nous proposons un cadre de référence pour le traitement du leadership dans une JBS.

Mots clés: Leadership, spiritualité ignatienne, écoles de commerce.

En los últimos años, se han realizado numerosos análisis y reflexiones sobre el liderazgo. Sin embargo, con mucha frecuencia se centran en la figura del propio líder, como si el hecho de ser un líder fuera en sí una función autosuficiente, que puede entenderse sin unos fines o con independencia de ellos (HeIFETZ, 1994). Y lo que debemos subrayar es que el liderazgo no es una posición que se ocupa, sino más bien una relación que se construye. Por otra parte, la cuestión acerca del líder ha motivado, con frecuencia, la deconstrucción de sus componentes, sin ninguna consideración acerca de cómo se reconstruye su combinación en la realidad, como si dicha reconstrucción acaeciera de manera automática. Finalmente, la reflexión sobre el liderazgo se presenta a menudo como si éste pudiera entenderse al margen de las situaciones, los proyectos y los contextos específicos en los que se produce (QUATRO ET AL., 2007). En último término, pues, la cuestión del liderazgo no se reduce simplemente a la cuestión del líder; ciertamente la incluye, pero es mucho más global. 


\section{El contexto en el que se desarrolla el debate del liderazgo}

Antes de entrar en la temática del liderazgo, es necesario no perder de vista el contexto en el que emergen algunas de las cuestiones que vamos a tratar. Las sociedades posindustriales, sin la referencia englobante e indiscutible (desde el punto de vista normativo) de las ideologías y las religiones (VALADIER, 1997), y sometidas a retos y amenazas colosales (producto no de las fuerzas de la naturaleza, sino de la misma actuación de los humanos; BECK, 1992 y 2000), necesitan para su supervivencia desarrollar la capacidad de trabajar con valores y de construir proyectos que no estén alimentados y alineados únicamente por objetivos, sino que incluyan la construcción de sentido (WEYICK, 1995; CORBí, 2007). A falta de referencias universalmente aceptadas y de guías para la acción admitidas como un "a priori" inmune a los retos que el propio desarrollo de la acción genera, la pregunta por el desde dónde se plantean los valores y los proyectos pasa a ser primordial. Un desde dónde que se refiere, a la vez, a personas, procesos y organizaciones, y a la calidad de estos tres elementos.

Este reto -vinculado a una conciencia clara de los nuevos retos de la globalización- viene intensificado por lo que la encíclica Caritas in veritate (CV, a partir de ahora) denomina el estallido de la interdependencia planetaria (CV, 33). Estos retos se condensan, en primer lugar, en la gobernanza y, en segundo lugar, en una aproximación a la responsabilidad ya no únicamente desde la clave causa-efecto, sino desde la perspectiva de la interdependencia (HELD y MCGREW, 2007).

El reto de la gobernanza nos plantea que debe evitarse que la lógica mercantil se amplíe a todos los ámbitos y colonice la manera de solucionar los problemas sociales, puesto que los modelos de competitividad se vinculan y se realizan en la diversidad de culturas y deben tenerlas en cuenta: la CV lo califica como la necesidad de civilizar la economía y el mercado. Pero afrontar la interdependencia requiere un enfoque más relacional que jerárquico de la gobernanza. De ahí la necesidad de gobernar la globalización, necesidad que no debe confundirse con un gobierno global: la gobernanza es un proceso que involucra diversos actores, y no supone necesariamente la creación de un actor de mayor volumen que los ya preexistentes. Pero esta asunción del reto de la gobernanza es inseparable de la asunción del reto de la sostenibilidad. No sólo hay que gobernar responsablemente la globalización, sino también la naturaleza, puesto que globalización y sostenibilidad han pasado a ser dos caras de una misma moneda. $Y$ hemos de tener en cuenta que este "gobernar" ya no se sitúa exclusivamente en el ámbito de lo político, sino que se abre al terreno de las responsabilidades compartidas (LOZANO, 2009). Es esta problemática la que está directamente vinculada a los 
nuevos modos de entender los liderazgos, puesto que no es lo mismo pensar los problemas económicos y sociales conforme a los paradigmas del siglo XX (relación con el gobierno) que hacerlo con los del siglo XXI (relación con la gobernanza). ${ }^{2}$ La respuesta que se dé a estas cuestiones marcará decisivamente el modo de entender no sólo los liderazgos, sino también su relación con el bien común.

Todo lo anterior, pues, afecta directamente a los liderazgos y a las dinámicas organizativas. Pensemos, por ejemplo, en la necesidad de crear cohesión y compromiso en organizaciones complejas, donde convergen personas con formaciones, contextos culturales y marcos valorativos muy diferentes entre sí, o en la necesidad, reiterada hasta convertirse en tópico, de formular declaraciones que, bajo distintas formas retóricas (los valores de la empresa, la visión, la misión), intentan catalizar la implicación personal de los miembros de la organización en un proyecto supuestamente colectivo, unidas a la habitual sensación de frustración y escepticismo que estas declaraciones generan, o finalmente en propuestas que plantean si es posible la gestión del conocimiento sin trabajar las capacidades de conocimiento y de autoconocimiento de las personas involucradas.

\section{La progresiva omnipresencia del liderazgo}

Todo lo que se refiere al liderazgo tiene fronteras borrosas y es objeto de enfoques muy diversos (HORNer, 1997). Pero, curiosamente, uno de los rasgos que caracterizan la evolución de su comprensión, dentro de esta diversidad, es un cierto interés por la pregunta acerca de la calidad del liderazgo (BADARACCO, 2002; CIULLA, 2005a). En sus orígenes, el estudio del liderazgo era prácticamente el estudio del líder. Dicho estudio habitualmente se ha llevado a cabo con un tipo de circularidad metodológica que ha predominado en las escuelas de negocios. Esta circularidad consiste, en síntesis, en observar qué maneras de proceder han tenido éxito -otra palabra cuyo contenido se da por supuesto y nunca se cuestiona-, analizar y desmenuzar estas maneras de proceder, $y$, finalmente, retornarlas, ya convertidas en normativas: si se supone que esto ha tenido éxito, esto es lo que habrá que hacer para tener éxito. Se empezó, pues, analizando a los grandes personajes, atendiendo a los rasgos que les conferían grandeza y, posteriormente a su personalidad (SAUQUET, 2008). No simplemente en sí mismos, sino por la influencia que tenían en el grupo de seguidores. Posteriormente, se

\footnotetext{
${ }^{2}$ He desarrollado con detalle este argumento en mi libro La empresa ciudadana como empresa res-
} ponsable y sostenible, 2009 
analizó también el tipo de influencia que tenían sobre el grupo y hacia dónde lo dirigían: aquí se incorporó la pregunta sobre cómo el líder aglutina a un grupo y lo dirige hacia un objetivo compartido. Más adelante, el punto de atención dejó de ser saber qué tipo de persona puede ser líder, y se atendió también a cómo actúa. Y este cómo se constata que es una combinación (en proporciones diversas) de atención a las personas y atención a las tareas. En una fase siguiente, se incorporó la atención al contexto: ser líder no es algo cuasi-sacramental, sino que se entiende en función de las circunstancias, que son las que facilitan o no la emergencia de determinados liderazgos (BADARACCO, 1998). A medida que avanzamos hacia una mayor complejidad (hacia la sociedad posindustrial), el liderazgo se revela también como algo cada vez más complejo, en la medida en que las personas también empiezan a vivir identidades y pertenencias múltiples (BARRATT y KORAC-KAKABADSE, 2002). De ahí que el liderazgo pasara a verse como creador de cultura, orientación y sentido (es decir, se remitiera a valores), y no simplemente de pautas de conducta y líneas de actuación (LOZANO, 1999; WADDOCK, 2007). Y, acto seguido, surge la pregunta por la calidad ética del conjunto: ¿Qué es lo que califica el cambio que se propone?, ¿qué visión moviliza?, ¿qué legitimidad tiene la relación que se establece con los diversos stakeholders?

En este proceso, cabe destacar tres aproximaciones en las que resuena el eco de lo que nos ocupa.

En primer lugar, la distinción entre liderazgo transaccional y transformacional (EISENBACH et al., 1999; SARROS Y SANTORA, 2001). El liderazgo transaccional se da cuando los líderes movilizan mediante la lógica del intercambio. El transformacional, cuando el liderazgo promueve una orientación que va más allá del propio interés, y eleva el nivel de conciencia y de propósito con relación al objetivo compartido (algo que, a menudo, se presenta vinculado al desarrollo de la inteligencia emocional). Parece intuitivamente obvio que las capacidades - pero también la calidad-requeridas en ambos casos son sustancialmente diferentes.

En segundo lugar, la concepción del "servant leadership" (GreenleAF, 1977; SpeARS, 2002; DelisLe y RINFret, 2006), que pone el acento en el servicio, más que en el liderazgo. Se supone que el líder es prioritariamente un servidor; e, incluso, que es líder porque previamente ha sido servidor. Un servidor que hace especial hincapié en aquello que es capaz de despertar en sus seguidores para ponerlos en camino. Pero en este camino no le siguen propiamente a él sino en la medida en que responden a la dimensión más noble de sí mismos, que el líder despierta y moviliza. El líder servidor, por tanto, lo es en la medida que en él resuenan la 
lucidez, la serenidad, la ecuanimidad y una actitud de respuesta a los retos del entorno y del grupo, con el deseo de hacer cosas grandes.

Finalmente, el liderazgo responsable (MAAK Y PLESS, 2006) emerge ante el progresivo reconocimiento de que, para aproximarnos al liderazgo, debemos ir más allá de su descripción, para centrar el enfoque en su calificación, también desde una clave de lectura ética. El liderazgo responsable parte del supuesto consecuencialista de que no es deseable cualquier tipo de liderazgo. Pero lo importante es que, para describir este tipo de liderazgo, apela a parámetros eminentemente cualitativos, en el marco de un enfoque relacional: el líder debe cuidar de los valores compartidos, de las comunidades en las que actúa; servir a los demás, y ofrecer inspiración y perspectiva sobre el futuro deseado. Para ello debe convertirse en arquitecto de estructuras y procesos, agente del cambio transformador; dar apoyo a sus seguidores, y crear sentido y significado. Con independencia de si es posible concentrar en una persona este ramillete de virtudes, sorprende que un perfil tan orientado a lo cualitativo no se pregunte en qué consiste la calidad última del sujeto sobre el que pueden sostenerse todas estas cualidades.

Por mi parte, he contribuido junto con À. Castiñeira y R. Ribera a este debate, insistiendo en dos puntos. En primer lugar, que no hay que confundir el liderazgo con el líder. Es decir, el liderazgo no es una posición que ocupa una persona, sino un proceso en el que hay que tener en cuenta, de manera inseparable, a la persona del líder, a los seguidores, a la causa que los aglutina y a los medios que utilizan. Pensar el liderazgo, por tanto, es pensar estos cuatro elementos y sus interrelaciones. En segundo lugar, la pregunta relevante no es la pregunta por el liderazgo, sino la pregunta por el buen liderazgo (CIULLA, 2005b; CASTINEERA Y LOZANO, 2009), porque, en caso contrario, no es posible resolver lo que denominamos la "paradoja Hitler-Gandhi", que consiste en que la mayoría de definiciones de liderazgo son aplicables, por igual, a ambos personajes y no permiten distinguir entre ellos, lo que, si no invalida dichas definiciones, sí repugna al sentido común (CASTINEEIRA y LOZANO, 2009). Y ello nos lleva a preguntarnos por la calidad humana del liderazgo: la de los líderes, la de la relación con sus seguidores, la de las causas y la de los medios que utilizan. El reduccionismo de pensar el liderazgo atendiendo en exclusiva a la figura del líder sólo puede ocasionar distorsiones. Y, en relación con el tema que nos ocupa, no hay que olvidar que la concepción de liderazgo desde la que se parte tiene inmediatamente una incidencia directa en el enfoque que se adopte desde una perspectiva educativa. 


\section{GRÁFICO I: Componentes del liderazgo}

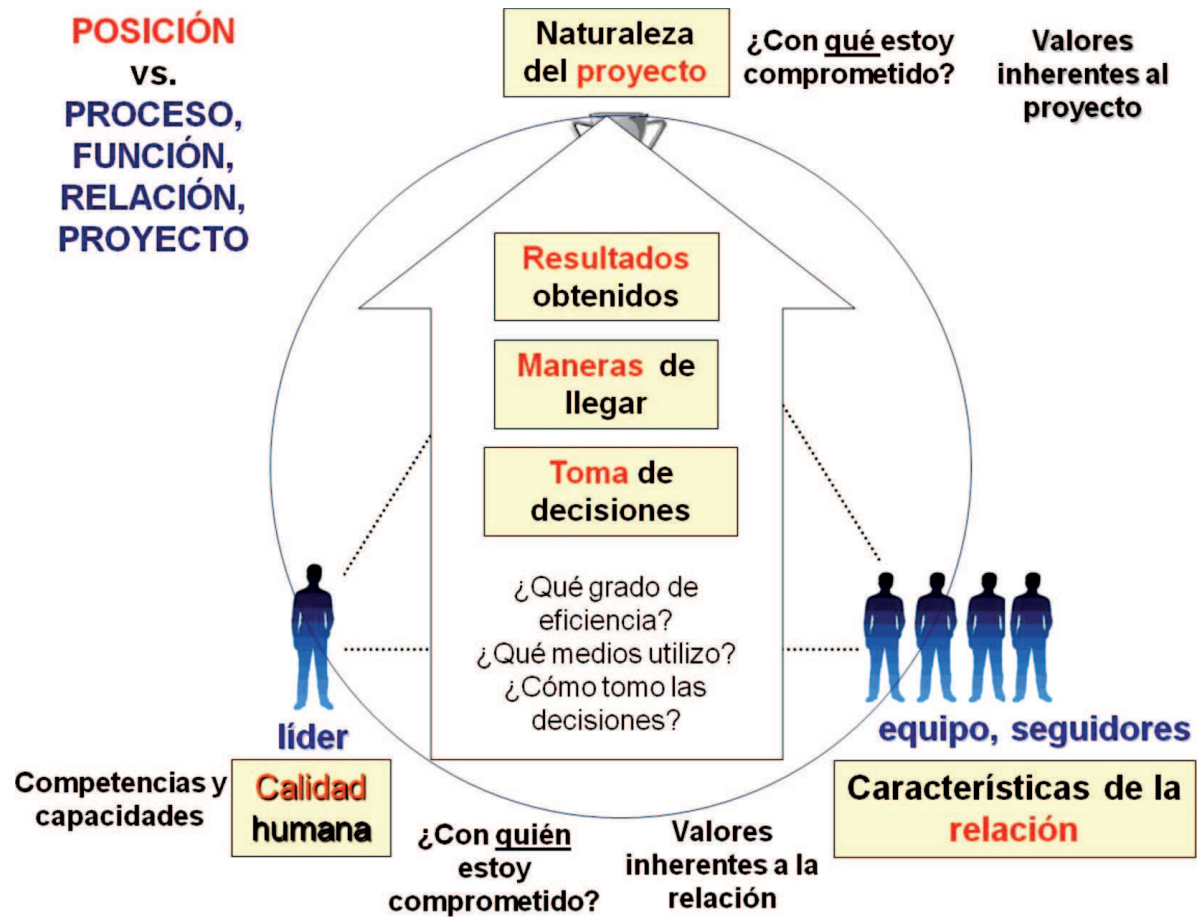

Fuente: CastiñeIRA y LozANo (2009) y Ribera (2008).

Así pues, el liderazgo no puede entenderse únicamente desde una perspectiva técnica $\circ$ instrumental. No es una mera habilidad relacional que simplemente requiere el desarrollo de unas competencias. El ejercicio del liderazgo siempre incluye -de forma explícita o implícita- una conexión con los valores. El liderazgo siempre supone una acción de creación de sentido ("sensemaking"). Por tanto, el desarrollo del liderazgo es imposible sin un proceso personal que desarrolle la capacidad de percepción, aprendizaje, interiorización y creación explícita de sentido, y de construcción de significado (COVEY, 1992; WEICK, 1995). Así pues, la auténtica pregunta no se limita simplemente a la cuestión del liderazgo, sino que debe transformarse en una pregunta acerca de lo que se ha venido en denominar buen liderazgo. $\mathrm{O}$, en palabras de Kolvenbach, no es cuestión de preparar líderes, sino más bien "líderes-para-servir". 
En la perspectiva que estamos proponiendo, el reto para un liderazgo que sostenga valores fuertes incluye cuatro componentes y sus interrelaciones. Estos componentes (reflejados en la figura "componentes del liderazgo") son: el líder, los seguidores, el proyecto y los medios para alcanzar los objetivos. En consecuencia, necesitamos preguntarnos cómo desarrollar los siguientes aspectos:

1. No sólo las competencias y habilidades de los líderes, sino también su calidad humana.

2. No sólo las características y la implicación de los seguidores, sino también sus relaciones, sus compromisos y sus valores.

3. No sólo la formulación de los objetivos del proyecto, sino también su coherencia ética.

4. No sólo el éxito al lograr los objetivos del proyecto, sino también los medios utilizados para alcanzarlos.

\section{Al final, ¿con qué tipo de persona nos encontramos?}

Volvamos, pues, al contexto. Queda pendiente de realizar una reflexión que aclare por qué en los últimos años los únicos valores éticos que han adquirido relevancia pública han sido los valores de carácter relacional, como por ejemplo, el diálogo y la responsabilidad. Insisto en que me refiero a los valores éticos que remiten a lo público, no a la vida privada. Sería necesario, por ejemplo, explorar a fondo qué significa que dichos valores públicos sean valores procedimentales, y no sustantivos, y que su punto de partida sea propiamente el hacer humano en una doble dimensión: qué hacemos con nuestras palabras y qué hacemos con nuestros actos. Deberíamos analizar en profundidad lo que podríamos denominar las condiciones socio-culturales que hoy hacen posible el éxito de estos dos valores relacionales en el ámbito público. No es éste el lugar ni el momento de hacerlo, sino de mostrar la relación existente entre esta cuestión y el tema que nos ocupa.

Muchas de las reflexiones que en los últimos años han intentado dar cuenta de la atmósfera en que vivimos en lo referente a los valores, han coincidido en señalar que la característica principal es la de no compartir un marco de referencia valorativo -de carácter sustantivo- común. Coinciden en ello, desde supuestos muy diferentes, los discursos sobre la posmodernidad (LYOTARD, 1984; VATIMO, 
1985), la modernidad líquida (BAUMAN, 2000), el comunitarismo (TAYLOR, 1993), la virtud (MAClNTYRE, 1981), la anarquía de los valores (VALADIER, 1997), la épica de la subjetividad (GOMÁ, 2003) o el crepúsculo del deber (LIPOVETSKY, 1992), por mencionar algunos ejemplos. Por otra parte, los análisis sobre los procesos de globalización no han dejado de señalar las amenazas que ésta supone, bajo la forma de denominaciones como la sociedad del riesgo (BECK, 1992), un mundo desbocado (GIDDENS, 2000), la corrosión del carácter (SENNET, 1998) o las preguntas sobre de si podremos vivir juntos (TOURAINE, 1997), si podremos hacer del mundo un lugar para todos (BARBER, 1998) o si podremos vivir en una buena sociedad (ETZIONI, 2001), hasta el punto de que podemos afirmar que, cuando JONAs (1992) habló de una heurística del miedo, no hizo sino anticipar lo que se ha convertido en un rasgo constitutivo de la mentalidad de nuestro tiempo.

La conjunción de una falta de referencias valorativas compartidas, por una parte, y el sentimiento de que la humanidad ha generado, simultáneamente, un potencial colosal de oportunidades y amenazas es lo que ha permitido, en mi opinión, que emergiera con la fuerza de una evidencia la pregunta y la "pre-ocupación" por las consecuencias de las acciones humanas. Quizá no tenemos valores compartidos, y la mirada al futuro despierta en nosotros temor y expectativas con la misma intensidad. Pero incluso viviendo en el pluralismo axiológico, lo que nadie puede negar es que todo lo que hacemos tiene consecuencias. Consiguientemente, por simplificador que parezca, cualquier intento de comprender la acción humana arranca del hecho incontrovertible de que no hay acción sin consecuencias. Y, por tanto, la pregunta por las consecuencias de la acción humana resulta uno de los pocos terrenos comunes sobre los que construir el discurso ético cuando no disponemos de un acuerdo de partida sobre los valores: las consecuencias pasan a ser el factum incontrovertible de la acción humana. La pregunta por las consecuencias parece que genera fácilmente un discurso ético en clave de diálogo y responsabilidad. Y conviene no despreciar la fuerza que la pregunta por las consecuencias tiene para interpelar directamente la conciencia moral. Porque responde a la inmediatez de la acción. Hoy podríamos afirmar también, como hiciera Goethe, que en el principio era la acción (y no los valores, la moral o la religión).

Este enfoque a la acción explica, probablemente, el éxito de la responsabilidad social de la empresa (RSE), incluida la diversidad de sus planteamientos (WINDSOR, 2001; LOZANO, 2009). Porque, inmersos en la acción y en la toma de decisiones, sus protagonistas se ven "a priori" más capaces de atender a las consecuencias (CARROLL, 1999) de sus acciones que de entender los valores que las rigen. Y más en nuestro contexto de politeísmo de valores, en el que los valores parecen poco operativos y poco clarificadores como criterios para la acción, en la medida en 
que aparecen como controvertidos socialmente, condicionados culturalmente y sobrecargados de abstracción. No es casual que el tratamiento de uno de los referentes conceptuales de la RSE, los stakeholders, casi se agote en la pregunta sobre quién y cómo se ve afectado por las actuaciones empresariales; o cómo los stakeholders pueden afectar a la empresa. Y, sobre todo, no es casual que el enfoque pragmático de las relaciones con los stakeholders casi se confunda con esta pregunta (Freeman, 1999). Aún queda pendiente de análisis un curioso juego de suma cero que ha ocurrido en los últimos años, en los que cuanto más se ha hablado de RSE, menos se ha hablado de ética empresarial.

Se confirma que algo no funciona en la pretensión de que el discurso sobre la RSE sea autosuficiente (BEAUCHEMIN, 2006) y quiera sostenerse sobre sí mismo si lo contrastamos con lo que ha ocurrido en los últimos años en el análisis del liderazgo. Sintomáticamente, la pregunta por el liderazgo es también una pregunta que remite, necesariamente, a la acción: si no hay acción, no hay liderazgo. Ahora bien, también remite, intrínsecamente, a los valores: no hay liderazgo sin proyecto, finalidad ni visión. Hasta el punto de que resulta entre paradójica y sintomática la insistencia de algunos autores en querer poner tierra por medio afirmando, a la vez, que los valores son un elemento constitutivo del liderazgo pero que lo que ellos plantean en sus análisis no entra, bajo ningún concepto, en el territorio de la ética (JENSEN, 2007). En este territorio, en cambio, sí que entra, a través de una visión más poliédrica del liderazgo, lo que hoy se denomina liderazgo responsable, expresión cuyas dos palabras pretenden tener el mismo peso y densidad. En cualquier caso, con ética o sin ella, ya hemos visto que la reflexión sobre el liderazgo no se reduce únicamente a la reflexión sobre el líder, sino que ha desembocado en la reflexión sobre el buen liderazgo. Es decir, sobre todo el proceso de relaciones que el liderazgo comporta, y sobre los valores y la calidad humana que lo configuran.

Creo que desarrollar a fondo una comprensión correcta del buen liderazgo y del liderazgo responsable es un reto y una necesidad, pero conseguirlo no es suficiente. Sería necesario complementarlo con una consideración sobre lo que significa ser un ejemplo o ser un referente. ¿Por qué? Porque, de manera similar al discurso sobre la responsabilidad, pensar la ejemplaridad o la referencialidad comporta adoptar también, como punto de partida, la acción humana, pero desde otra perspectiva. Así como al hablar de la responsabilidad nos hemos referido al factum de las consecuencias, al hablar de los ejemplos y de los referentes el punto de partida es el factum de las influencias. En otras palabras: no todos podemos ser líderes, pero todos podemos ser referentes (GOMÁ, 2003, 2009), y ahí se juega también nuestra responsabilidad. 
Todos vivimos nuestras vidas entrelazados por una red de influencias mutuas de la que no podemos escapar. Nuestra identidad personal es el resultado de procesos más o menos conscientes de "identificación con" o de "rechazo de" atributos parciales o globales de las personas con las que interaccionamos y que nos influyen (SARROS Y SANTORA, 2001; GOMÁ, 2003). A través de nuestra manera de hacer, construimos nuestra manera de ser, ciertamente, pero nos vamos modelando a nosotros mismos a partir de la relación con la manera de hacer y de ser de las otras personas con quienes interaccionamos. Todos somos, de hecho, continuamente ejemplo y referencia los unos para con los otros (GOMÁ, 2003). Si ello es así, entonces la pregunta por la responsabilidad se complementa con y se transforma en la interpelación para ser un buen ejemplo (o un buen referente). Porque todo lo que hacemos no sólo tiene consecuencias desde el punto de vista de los efectos, sino también desde el punto de vista de los afectos. El referente no lo es sólo por su actuación, sino por el vínculo y la atracción afectiva que su acción genera en los demás. Porque nuestra acción siempre da lugar -continua y simultáneamente- a consecuencias fácticas y a interpretaciones experienciales. Nuestra acción siempre genera efectos y afectos -estén o no bajo nuestro control y dependan o no de nuestra voluntad consciente- - y no podemos pensar la acción humana sin pensarlos a ambos. Por consiguiente, no podemos pensar la responsabilidad sin pensar en los efectos y en los afectos que generamos. $Y$ no podremos educar para la responsabilidad y el liderazgo si atendemos sólo a la educación de los efectos y olvidamos la educación de los afectos.

Reivindicar la necesidad de referentes no se basa en el supuesto "descendente" de que concretan y encarnan unos valores abstractos y universales. Más bien se trata del testimonio -en clave hermenéutica- que acontece en la experiencia visible de una especie de prototipo humano: la visualización integrada de ser, poder ser y deber ser (GOMÁ, 2009), que configura lo que se puede calificar, según cada caso, como un buen (o un ejemplo de) directivo, profesional, investigador, profesor, etc., y también como una buena (o un ejemplo de) empresa, organización, asociación, ONG, etc. Los ejemplos y los referentes no lo son por la perfección que muestran, sino por la inspiración que transmiten, y lo que generan no es el deseo de copiarlos, sino de autotransformarse en sintonía con su inspiración.

Nuestra época, como Fausto, sólo es capaz de aceptar, como una asunción compartida, que en el principio era -y es- la acción. La novedad que ha hecho eclosión en los últimos años es que la acción no requiere preguntarse únicamente sobre qué hacemos con nuestras palabras y con nuestros actos, sino también ly cada vez más) quién es el que habla y el que actúa y, por consiguiente, plantear que la calidad de su acción tiene una cierta correlación con su calidad personal 
(Senge et al., 2004; Harle, 2005; Pruzan et al., 2007). Por tanto, la construcción de la calidad humana ya no es un asunto que se deje al azar o a la casualidad de cada biografía personal, sino que pasa a ser un asunto vinculado a la vida pública y al desarrollo organizativo (WADDOCK, 2001; Corbí, 2007; Pruzan et Al. 2007).

Consiguientemente, la calidad humana de las personas y los valores que las configuran pasan a ser temas prioritarios para el desarrollo de las organizaciones, especialmente si dichas personas ejercen las funciones del líder (WADDOCK, 2001; CORBí, 2007). Y, por tanto, son también un reto para cualquier proyecto educativo, especialmente para aquellos que incluyen la orientación al liderazgo como una de sus características.

\section{Elementos para una aproximación al liderazgo desde la perspectiva de la espiritualidad ignaciana}

Así pues, en el contexto de nuestras sociedades complejas, el reto para educar un liderazgo que sostenga valores fuertes implica trabajar sobre cuatro componentes y sus interrelaciones. Estos componentes, como hemos señalado, son el líder, los seguidores, el proyecto y los medios para alcanzar los objetivos. Pensar el liderazgo y trabajar para su desarrollo requiere actuar en estos cuatro niveles, y desarrollar capacidades para integrarlos. No se trata, pues, de reducir la formación para el liderazgo a la formación del líder. Porque las Jesuit Business Schools (Escuelas jesuitas de administración y dirección de empresas) ${ }^{3}$, antes que formar a líderes, tienen que formar a personas completas, desde el supuesto de que la persona completa, ideal de la educación jesuítica durante más de cuatro siglos, será, en el futuro, una persona competente, consciente, capaz de compasión y bien educada en la solidaridad. ${ }^{4}$ Es decir, una persona con capacidad para actuar cada vez con más atención a su conciencia, a los efectos de su acción y a los afectos que la mueven. La persona debe estar en el centro del proceso de formación (FLORENSA, 2008), no simplemente el líder, el gestor o el profesional.

Por tanto, recordemos de nuevo que en la educación para el liderazgo lo que tenemos que plantearnos es cómo desarrollar los siguientes aspectos:

3 Jesuit Business Schools, a partir de ahora JBS.

${ }^{4}$ KolvenBACH, Roma, 2001. (Todas las citas de Kolvenbach se han extraído del libro Discursos universitarios, Madrid 2008, que contiene todos los discursos que pronunció sobre esta temática.) 
a. No sólo las competencias y habilidades de los líderes, sino también su calidad humana.

b. No sólo las características y la implicación de los seguidores, sino también sus relaciones, sus compromisos y sus valores.

c. No sólo la formulación de los objetivos del proyecto, sino también su coherencia ética.

d. No sólo el éxito al lograr los objetivos del proyecto, sino también los medios utilizados para alcanzarlos.

Si la educación para el liderazgo debe desarrollar estas cuatro dimensiones, ello es especialmente relevante para una JBS, especialmente si tenemos en cuenta que la reflexión y el análisis sobre el liderazgo han creado, por lo general, comparativamente muy poca reflexión y análisis sobre los seguidores y el seguimiento (GoffeE ET AL., 2006; KARK Y VAN DIJK, 2007) y -en un contexto académico- sobre el discipulado. Esto supuesto, la invitación al "magis" (DECLOUx, 2001) no debe confundirse simplemente con prestar atención a aquellos que se hallan en la cima de la pirámide de la organización: El magis apunta ciertamente a los líderes de mañana, que la sociedad humana necesita, pero sin hacer de ellos una secta de gente segregada, marcada por el elitismo. ${ }^{5}$ Ello significa que, en la medida en que la configuración del liderazgo es un proceso en constante evolución, resultado de influencias mutuas y de un desarrollo personal (ambos indisociables), es muy importante complementar la búsqueda de la excelencia con una apelación a la ejemplaridad, especialmente en las universidades y las escuelas de negocios. Porque, cada vez más, las organizaciones necesitan personas que no sólo sean excelentes, sino también ejemplares: hoy no hace falta recordar que muchos fracasos profesionales y organizativos son el resultado de la falta de ejemplaridad, y no simplemente de la falta de liderazgo.

Nosotros queremos graduados que estén dispuestos a ser líderes preocupados por la sociedad y el mundo, deseosos de acabar con el hambre y a los enfrentamientos en el mundo, que capten la necesidad de una más equitativa distribución de la munificencia de Dios, buscando la forma de acabar con la discriminación sexual y social, impacientemente decididos a compartir su fe y amor de Cristo con los otros. En definitiva, queremos que nuestros graduados sean líderes-para-servir. Éste ha sido el objetivo de la educación jesuita desde el siglo XVI y sigue siéndolo hoy. ${ }^{6}$

${ }^{5}$ KolvenBACH, Chile, 2006.

${ }^{6}$ KOLVENBACH, Georgetown, 1989 (subrayados en el original). 
Ahora bien, si de lo que se trata es de formar a líderes-para-servir, la paradoja de la formación en liderazgo desde la tradición jesuita es que no ha de centrarse en el liderazgo, sino en el servicio. Se necesita liderazgo, porque el servicio lo requiere, pero convertirse en líder no es una finalidad en sí misma que, una vez alcanzada, tengamos que decidir hacia dónde se orienta ${ }^{7}$. Se invierten los términos: el liderazgo es una respuesta posible a la llamada hacia lo que es prioritario: el servicio.

Una universidad jesuita debería conseguir transformar a sus estudiantes en mujeres y hombres para los demás, como el P. Arrupe repitió con tanta frecuencia, pero también, y mucho más en nuestros días, en mujeres y hombres con los demás. [...] Desde su mismo inicio, la educación jesuita ha consistido en una lucha por la dignidad humana y los derechos humanos, la libertad ilustrada de la conciencia y la libertad responsable de la palabra, el diálogo respetuoso y una paciente promoción de la justicia. ${ }^{8}$

Ello significa que, desde la perspectiva de la tradición jesuita, sería una buena idea revisar la forma en que se ha abordado la formación de profesionales reflexivos (SCHÖN, 1987) en términos de excelencia y ejemplaridad, y también revisar qué se entiende por un profesional reflexivo. Si es cuestión de ayudar a los hombres a ser más auténticamente humanos, en la plenitud de la dignidad humana, activos participantes en la construcción de un mundo mejor, ${ }^{9}$ ello plantea la cuestión de sobre qué temas se debería reflexionar y sobre qué debería ser capaz de reflexionar un profesional reflexivo (entendiendo por "reflexión" no sólo un simple ejercicio intelectual sino una amplificación y afinación cada vez mayores de la conciencia y la sensibilidad). En este sentido, conviene recordar que, en la tradición ignaciana, el liderazgo no puede separarse del autoconocimiento (LOWNEY, 2004). ¿¿Qué criterios, pues, deberían tenerse en cuenta en una educación para el liderazgo? Cuando Kolvenbach sugirió al comité directivo de la Universidad de Georgetown que el marco de referencia para entender y valorar una universidad conforme a la tradición jesuita eran la "utilitas", la "iustitia", la "humanitas" y la "fides" 10 , añadió que el liderazgo desempeñaba un papel esencial para alcanzar

\footnotetext{
${ }^{7}$ Que es el supuesto implícito en muchos, si no la mayoría, de los llamados programas de desarrollo del liderazgo.

${ }^{8}$ KOLVENBACH, Roma, 2007 (subrayados en el original).

${ }^{9}$ KOLVENBACH, Frascati, 1985.

10 Para una completa presentación del llamado "paradigma universitario Ledesma-Kolvenbach" y sus implicaciones, véase la precisa contribución de AGÚNDEZ (2008).
} 
este objetivo. Pero también podríamos darle la vuelta y decir que, para el desarrollo del liderazgo, estas referencias se convierten en sus criterios hermenéuticos. $Y$, en consecuencia, que el profesional reflexivo ha de ser una persona capaz de reflexionar y trabajar en las habilidades prácticas y los valores inherentes a su profesión; en los desafíos sociales, políticos y culturales que supone el ejercicio de su profesión; en la calidad de sus relaciones; y en su propia calidad humana (que incluye la apertura a la espiritualidad" y la búsqueda de significado y sentido). Si el criterio real de evaluación de nuestras universidades jesuitas radica en lo que nuestros estudiantes lleguen a ser, ${ }^{12}$ esto significa también que, para la educación jesuita, la regla para medir la calidad de una universidad es la calidad humana que alcanza el estudiante. ${ }^{13}$

De acuerdo con la tradición de la espiritualidad ignaciana, esto tiene que ser algo más que una mera actividad exclusivamente intelectual y/o académica. Una JBS debe ser un lugar donde sea posible llevar a cabo experiencias que faciliten - conduzcan a un crecimiento en la "utilitas", la "iustitia", la "humanitas" y la "fides". Y cuando hablo de un lugar, me refiero a la integridad de la educación del estudiante, y no sólo a los planes de estudios académicos (SPITZER, 2010). Y cuando hablo de experiencias, me refiero a procesos diseñados deliberadamente y buscados explícitamente, y no a los que encontramos fortuitamente en las personas que nos invitan a llevarlos a cabo. Preguntémonos, pues, y sobre todo como universidad que se reclama del Evangelio, qué tipo de hombres y mujeres necesitamos formar para que sean los líderes del tercer milenio. ${ }^{14}{ }_{\text {iPueden tener alguna }}$ utilidad los Ejercicios Espirituales para contestar esta pregunta? Si la respuesta es afirmativa, ¿̇consiste en algo más que en una reafirmación retórica y generalista de las declaraciones de valores y de la misión de una JBS?

\footnotetext{
"En este punto no coincido con los planteamientos sobre la calidad humana propuestos por mi colega R. RiberA en su artículo "Empresa y calidad humana" (2008), en el que excluye la espiritualidad de la definición de calidad humana.

12 KolvenBACH, Santa Clara, 2000.

${ }^{13}$ KolvenBACH, Chile, 2006.

${ }^{14}$ KolvenBaCH, México, 1990
} 


\section{Una lectura en clave antropológica de los Ejercicios Espirituales}

Con el fin de indagar y proponer varios criterios que permitan configurar esta cuestión, aventuro una revisión interpretativa de las anotaciones 18 y 19 de los Ejercicios espirituales (EE, a partir de ahora la referencia seguida de uno o más números remite al texto original). En ellas se plantea la posibilidad de ofrecer sólo unos pocos elementos de la primera y la segunda semanas de los EE (IGLESIAS, 1998), especialmente en lo que se refiere a los perfiles de dos tipos diferentes de personas: las muy ocupadas (al que estuviere embarazado en cosas públicas o negocios convenientes) y las personas más rudas o sin letras. El primer perfil, evidentemente, es muy común entre los asistentes a una escuela de negocios, que a menudo pretenden ser el paradigma de lo que es una persona muy ocupada. En lo que atañe al segundo perfil, en la actualidad podría reformularse diciendo que, en un contexto plural y posmoderno, una persona puede recibir una gran cantidad de formación especializada, y que ello sea compatible con una aproximación simple y primaria a la religión y a la espiritualidad, o que éstas simplemente puedan quedar excluidas de su marco de referencia vital. En otras palabras: hoy se puede exhibir una sofisticada especialización técnica y un exitoso curriculum y, a la vez, ser una persona ruda o sin letras en todo lo que se refiere al manejo de las emociones, a la conexión con los estratos más íntimos de la personalidad o a la elaboración del propósito y el sentido de la vida. Por esta razón, puede resultar necesario explorar una relectura en clave antropológica de los ejercicios propuestos en la primera y la segunda semanas, que podrían utilizarse como una heurística de lo que se propone ofrecer y trabajar en una JBS. De lo que se propone a todos los participantes, y no sólo a algunos de ellos, en función de sus creencias religiosas. Vamos, pues, a realizar un primer intento en esta dirección, examinando algunas de las potencialidades antropológicas y educativas de lo que en el lenguaje de los EE se denomina el prosupuesto, el principio y fundamento, el examen particular y general, el llamamiento del rey temporal y la meditación sobre la encarnación. ${ }^{15}$

Lo que propongo, pues, es una lectura antropológica (GARCíA, 2000) de algunas partes de los EE que San Ignacio consideraba apropiadas para las personas muy ocupadas y para las "rudas o sin letras" (OLENIACZ, 2001). Quiero simplemente añadir (puesto que no puedo desarrollar este punto aquí) que no contrapongo en

\footnotetext{
15 Inevitablemente, para no recargar en exceso el texto no me queda más remedio que dar por supuesta una mínima familiaridad con la terminología de los Ejercicios, cuyo uso creo que no impide una comprensión de las preguntas que planteo, más bien la facilita.
} 
absoluto una aproximación teológica y una antropológica, como si pudieran existir por separado: no hay teología fuera de alguna antropología. Lo que pretendo es utilizar algunos momentos de los EE como base para una indagación antropológica que tenga sentido por si misma, sin necesidad de expresarla en términos religiosos y/o cristianos (SEGUNDO, 1996; CORBí, 1998; SOLOMON, 2002; TUGENDHAT, 2004; MiRAlles, 2008)16, y de este modo considerarlos como una interpelación a determinadas prácticas de las JBS. Para ello, hago explícitas algunas preguntas (DonNely, 2010), que, desde mi punto de vista, vienen suscitadas por una lectura abierta y atenta de los mencionados apartados de los EE.

\section{I. Prosupuesto: “Todo buen cristiano...” (EE 22)}

San Ignacio arranca con un consejo que se dirige tanto a quien da como a quien recibe los EE. Pero este consejo-como todo lo que se produce en los EE- no queda restringido a un momento de los $\mathrm{EE}$, sino que tiene una finalidad estructuradora, vital. Y lo que estructura es, a la vez, una afirmación del proceso individual -personalizado-y el reconocimiento de que dicho proceso se da siempre en una estructura relacional. Una relación que, no por el hecho de respetar los itinerarios personales, deja de ser asimétrica: se trata de quien da los EE y de quien los recibe. Ello debería llevar a preguntarnos si los procesos educativos de las JBS están al servicio de las agendas individuales previas de nuestros alumnos: ¿̇satisfacen simplemente una demanda de formación? ¿ $\mathrm{O}$ sitúan claramente el proceso educativo en un contexto relacional cuyo reto es explorar todo lo que dé de sí la relación educativa que se establece y confrontar el alumno con retos y preguntas que acaso jamás se haya planteado? (BenNIS y O’TOOLE, 2005).

${ }^{16} \mathrm{Y}$ sin excluir que también se pueda expresar en términos religiosos o cristianos, claro está. No me cabe duda que para quien se aproxime a estos momentos de los Ejercicios desde una matriz creyente, el intento quizá pueda parecerle una devaluación o una pérdida de tiempo. Lo primero, evidentemente, depende de la perspectiva adoptada, y lo segundo depende de las prioridades de la agenda de cada cual. Ahora bien, si se considerara una pretensión imposible de raíz, entonces creo que el problema no lo tendría yo (lo que no tiene ninguna importancia) sino el propio proyecto de llegar a ser una JBS. ETXEBERRía (2008) ha diseccionado, con la finura y precisión habituales de su bisturí intelectual, la cuestión de la "Fides". En algunos puntos mis planteamientos no coinciden exactamente con los suyos, aunque creo que a veces las diferencias son quizá sólo de acento y de foco. Pero mi objetivo aquí no es volver sobre la cuestión que él plantea, sino tomarme en serio una de sus referencias: el camino ignaciano, que lo inspira todo (p. 706). De manera deliberada, mi cita no recoge su frase completa, y soy consciente de ello: pero mi indagación pretende tomarse radicalmente en serio el todo (que incluye a todos). Dicho con otras palabras, se trata de explorar cómo concretar la atención y el trabajo directo y explícito sobre lo que MIRALLEs (2008) denomina el espíritu humano en la articulación entre "utilitas", "iustitia", "humanitas" y "fides". 
En este sentido, el prosupuesto pone el acento en la capacidad de atender, entender, escuchar y comprender lo que dice el otro. La voz del otro se convierte en la referencia, no el propio monólogo interior. Más allá de la mera tolerancia pasiva, la receptividad. ¿̇Receptividad ante quéé Ante la declaración del otro. Aquí la palabra original castellana resulta indispensable: proposición, pues va más allá de una simple declaración. Porque proposición contiene, indisolublemente, dos sentidos: uno cognitivo y otro práctico. Una proposición es, a la vez, un enunciado (qué me dice el otro) y una propuesta (qué me invita a hacer el otro). Y San Ignacio nos dice que todo buen cristiano ha der más pronto a salvar la proposición del próiimo que a condenarla; y si no la puede salvar inquiera como la entiende; y, si mal la entiende, corríjale con amor; $y$, si no basta, busque todos los medios convenientes para que, bien entendiéndola, se salve. (EE, 22). Ello significa que las JBS deberían preguntarse continuamente, como uno de sus rasgos diferenciales (LOWNEY, 2010), qué proposiciones hacen a los estudiantes: qué mensajes y qué propuestas prácticas les dirigen; sobre qué les invitan a pensar y qué les invitan a hacer. Esta actitud de apertura y receptividad es una condición previa, pero no en sentido cronológico, sino en sentido fundamental, por lo que debería trabajarse a lo largo de todo el proceso educativo de una JBS. Si se trata de aprender a escuchar y aprender a entender, ¿̇escuchar y entender a quién? ¿¿Qué voces y qué mensajes pueden oírse en las JBS? Los estudiantes $i$ se encuentran sólo con proposiciones que encajan con lo que convencionalmente se dice y se hace en cualquier escuela de negocios? Los mensajes y las propuestas que reciben $\dot{\partial}^{\text {son }}$ los que podrían encontrarse en cualquier otra escuela de negocios? Es decir, ¿̇experimentan una transformación para ser cada vez más receptivos, o bien lo que reciben no es más que el reflejo de lo convencional; un simple juego de espejos del mundo de los negocios, encerrado en sí mismo? Porque, por cierto, no puede haber receptividad allí donde sólo hay repetición de lo que ya está establecido.

Escuchar las proposiciones presupone un enfoque relacional multidimensional, frente a la mera transmisión de conocimientos o a una mera relación comercial basada exclusivamente en la orientación al cliente: una universidad es algo más que una empresa de servicios formativos. La estructura relacional que fundamenta el itinerario personal que son los EE requiere poner el acento en una actitud de búsqueda compartida, en el contexto asimétrico de la relación educativa. Por tanto, la pregunta para una JBS conectada con los EE no se limita a qué proposiciones realiza a sus estudiantes, sino que incluye todas las que reciben y hacen todos los estamentos de la institución (LOSADA ET AL., 2011). Entre otras razones, porque la calidad de las proposiciones que reciban los estudiantes estará en correlación con la calidad de las proposiciones que los docentes se formulen a sí mismos. Esta necesidad de ir más allá de un currículo reducido a un juego de espejos en el 
que los negocios se miran sólo a sí mismos es lo que, en mi opinión, subyace en la interpelación de KOLVENBACH: Tenemos que pagar un precio por autolimitarnos a entender la educación como una transmisión de cultura, más que como una crítica a la cultura. ${ }^{17}$ No hay educación para el liderazgo sin desarrollar ni cuidar la receptividad con respecto a las proposiciones de los demás, sin el esfuerzo de comprenderlas y sin la disposición a responder a ellas -en el sentido que sea-con libertad. Y por ello mismo no hay educación para el liderazgo sin capacidad de crítica de lo que está establecido y se da por obvio e inmutable.

\subsection{El principio y fundamento: “... solamente deseando y eligiendo...” (EE 23)}

El principio y fundamento es el pórtico de los EE (FESSARD, 2010). Pero un pórtico que no es una mera puerta de entrada, que después se deja atrás. Es el pórtico de todas y cada una de las etapas y las decisiones de la vida. Arzubialde señala acertadamente que nos hallamos ante un texto netamente antropológico, ${ }^{18}$ y es esto lo que hemos de explorar en toda su radicalidad. Porque es con esta radicalidad antropológica (GÓMEZ CAFFARENA, 1997; LIBANIO, 1997) que se deberá confrontar la propuesta educativa de las JBS. Fessard ha insistido en señalar que la experiencia - a la vez espiritual y antropológica- de los EE es un camino hacia la libertad, un camino que se desarrolla realizando actos radicales de libertad. Ahora que el debate sobre los valores profesionales que se proponen desde las escuelas de negocios se ha planteado explícitamente (KHURANA, 2007), desde la tradición ignaciana acaso se debería ir más allá, y plantear que toda la educación en una JBS tendría que venir marcada por la confrontación con el principio y fundamento, y convendría preguntarse si, sin esta confrontación, es posible hablar de educación en clave ignaciana.

¿En qué sentido puede afirmarse esto? Creo que en el énfasis de que el camino hacia la libertad es un camino que se articula en torno al propósito. El yo libre no es el resultado de ensanchar cada vez más los límites y el dominio territorial de este yo, sino el resultado de hacerlo cada vez más disponible para un propósito libremente elegido desde el des-centramiento y no desde la fantasía de omnipotencia. En otras palabras: no existe liderazgo al margen del principio y fundamento. El principio y fundamento arranca con un reto: El hombre es criado para... (EE, 23). Se trata pues de plantear explícitamente la pregunta por el fin

${ }^{17}$ Kolvenbach, México, 1990.

${ }^{18}$ ArZubialde (1991), 73. 
- el propósito de lo que hacemos y, más allá de lo que hacemos, de nuestro seren-el-mundo (GUERRERO, 1998). El riesgo de las JBS es situarse exactamente en el terreno opuesto: dar por supuesto que todos los participantes llegan con su propio propósito y que dicho propósito no es cuestionable (o no forma parte de lo que tiene que plantearse en una JBS). Como si la JBS únicamente ofreciera contenidos, capacidades y habilidades; medios, en definitiva ${ }^{19}$. No se trata en ningún caso, naturalmente, de pretender imponer un determinado propósito, pero sí de ayudar y acompañar a los estudiantes a confrontarse con la pregunta sobre su propósito (algo que muchos de ellos jamás han afrontado explícitamente), puesto que su propósito vital y profesional marcará al servicio de quién actuarán. Porque las otras cosas sobre la haz de la tierra son criadas para el hombre, y para que le ayuden en la prosecución del fin para que es criado (EE, 23). El sentido de todas las cosas viene dado por el propósito que anima las relaciones con ellas. Y las otras cosas incluyen también todo el currículo educativo.

No puede haber una JBS inscrita en la tradición ignaciana sin un currículo educativo de altísimo nivel y calidad. Pero no hay educación en la tradición de los EE sin confrontar a los participantes con la elaboración de su propósito personal y vital, y sin hacer de esta confrontación un camino hacia una mayor libertad. En un contexto social y cultural que venera el hecho de disponer de medios cada vez más sofisticados y rehúye la pregunta por los fines, dicha confrontación es lo que, en la expresión de KOLVENBACH antes citada, adopta hoy la forma de crítica a la cultura. De ahí la importancia del tanto cuanto: De donde se sigue, que el hombre tanto ha de usar dellas cuanto le ayudan para su fin, y tanto debe quitarse dellas cuanto para ello le impiden. (EE, 23). Arzubialde (1991) ha mostrado claramente cómo la estructura del principio y fundamento viene marcada por esta secuencia: en primer lugar, el fin (o propósito); en segundo lugar, la relación con las otras cosas, subordinadas al fin; en tercer lugar, el uso ordenado de ellas tanto cuanto nos acerca al fin o propósito.

Esta concepción plantea a toda JBS inscrita en la tradición ignaciana que ha de acompañar explícitamente a todos los estudiantes y les ha de facilitar que afronten su creación de propósito (frente a la mera recepción de conocimientos, capacidades y habilidades). $O$, dicho de otro modo, acompañar y ayudar (palabra también de fuerte resonancia ignaciana) a indagar, construir, descubrir, explicitar y comprometerse con el propio propósito profesional y vital es una dimensión esencial de la responsabilidad de una JBS. Más aún: en un momento de fuerte debate sobre

19 Lo cual no niega ni minusvalora la importancia de contenidos, capacidades y habilidades, por supuesto. Véase al respecto, HORTAL (2008). 
la contribución de las escuelas de negocios y sobre su propuesta educativa (BENNIS y O'TOOLE, 2005), esta puede ser una aportación diferenciada (LOWNEY, 2010) e identitaria de las JBS inscritas en la tradición ignaciana.

Pero esto sólo será así si esta actitud de acompañar, facilitar y ayudar no renuncia, si es preciso, a cuestionar y a confrontar. No basta con hacer emerger el propósito: hay que plantear el reto de la calidad humana del propósito. Entre otras cosas, porque los EE no se limitan a hablar del propósito en general o en términos enunciativos, sino que lo consideran indisociable de lo que queremos, deseamos y elegimos. El principio y fundamento nos habla de la libre elección, pero también nos dice que no hay libertad sin educación del deseo (MELLONI, 2009). Y, por tanto, que no hay -simplemente- educación sin educación del deseo. Existe siempre el riesgo de que hablar del propósito sea hablar de un ego cada vez mayor, donde el propósito no sea más que un yo ideal fusionado con este ego. El camino de la libertad es un camino que requiere una cada vez mayor lucidez ante las trampas del deseo, por lo que no se puede trabajar el principio y fundamento sin trabajar continuamente con los alumnos, en el día a día educativo, el ámbito de lo que debemos desear y elegir (EE, 23). En las JBS se habla mucho de objetivos y toma de decisiones, y muy poco de propósito y de discernimiento. Y no hay libertad sin propósito, pero tampoco sin discernimiento. ${ }^{20}$

Y ello nos lleva al último reto que plantea el principio y fundamento a las JBS: el reto de la indiferencia. No se trata, claro está, de una especie de desapego patológico, ni de desvincularse de todo apasionamiento, ni mucho menos de una versión cualquiera del todo vale. Se trata de ser, en palabras de ARZUBIALDE, activamente indiferente. Es, de nuevo, el tan repetido tanto cuanto. Se trata, pues, de hacer ver a los estudiantes que antes que la libertad para elegir viene la capacidad de hacernos a nosotros mismos indiferentes. Ahora bien, hacernos indiferentes a todas las cosas criadas (EE, 23) para elegir con mayor libertad el propósito y comprometernos auténticamente con él ¿̇puede ser un objetivo para una JBS? $\dot{i}$ Van a aceptarlo los estudiantes que se acercan a ella? ¿ Forma parte de lo se les ofrece cuando se "venden" y comercializan programas? La cuestión va más allá de lo que se propone a los estudiantes, y nos lleva inevitablemente (de manera análoga a como lo hace la pregunta por la RSE, como hemos puesto de relieve en LOSADA ET AL., 2011) a la pregunta de si el principio y fundamento es el pórtico de la manera de proceder de una JBS de inspiración ignaciana en todo su proyecto $y$ en sus estructuras organizativas.

20 Una reflexión sobre el aprendizaje del discernimiento en el contexto de una JBS requiere un estudio específico dedicado íntegramente a la cuestión, que ahora no puedo desarrollar aquí. 
En cualquier caso, sin embargo, lo que el principio y fundamento nos deja claro es que, en una JBS de inspiración ignaciana, no es posible hacer ninguna propuesta sobre el liderazgo sin confrontar críticamente a los estudiantes con la explicitación de su propósito profesional y vital, sin trabajar en la educación del deseo y sin activar la capacidad de indiferencia, precisamente como base para un compromiso apasionado.

\subsection{Examen individual y general (EE 24-43)}

Hablar hoy de examen puede parecer, literalmente, extemporáneo. Si por algo se caracteriza nuestro mundo (especialmente, el mundo de las empresas) es precisamente por la aceleración, la presión, la multiplicidad de tareas a las que dedicamos cada vez menos tiempo, de menor calidad, y menos atención. En un mundo en el que prevalece vivir de forma rápida, distraída y sin un propósito concreto, reivindicar lo que san Ignacio denomina examen es mucho más que un reto: es una llamada a cambiar los parámetros que configuran la acción. En este sentido, resulta ilustrativo recordar que Pedro Fabro ${ }^{21}$ otorgaba al examen la misma importancia que a la meditación, porque se ordenaba directamente al fin de los EE.

Pues ésta es la cuestión: hablar de examen no es hablar de revisar mecánicamente una lista de actividades o tareas. La tarea del examen sólo tiene sentido si se vincula al propósito. El examen es lo que permite que el propósito no quede reducido a una mera expresión genérica de buenos deseos, como los que nos proponemos cada fin de año, pues esto es justamente -como ha señalado KEGAN (2001 y 2009)- lo que oculta a menudo nuestra inmunidad al cambio. El examen tampoco es ni ejercicio autopunitivo ni ejercicio de cuantificación. El examen se refiere a la pregunta: " $\dot{Q} Q u i e ́ n$ soy y quién quiero ser?" $Y$ esta pregunta no puede dejar de estar presente en el horizonte educativo de una JBS. En otras palabras: proponer la práctica del examen es educar a las personas en la introspección y en el aprendizaje para que sean receptivas. Si nos hallamos en una JBS, la gente debería aprender que la acción requiere no ser simplemente y exclusivamente activo..., sino que también se necesita -como ya ha mostrado el prosupuesto de los $E E$ (EE, 22)- una receptividad activa, una disposición a ser receptivo ante la realidad y ante los demás.

${ }^{21}$ Beato (1506-1546), de origen saboyano, que formó parte del primer "grupo de París" de los fundadores de la Compañía de Jesús con san Ignacio de Loyola. (Nota del editor) 
En este sentido, afirmar el valor del examen presupone: tener un compromiso claro a favor de la excelencia; desarrollar la capacidad de hacer metódicamente una pausa para evaluar y concienciar el propio camino; y aprender a trabajar en las tendencias internas y externas que "nos mueven". La propuesta ignaciana de crear espacios para momentos de pausa durante el día (EE, 25) se confronta, sin duda, con un mundo profesional y una visión de la educación que nos hacen trabajar bajo presión e ir rápidamente de una cosa a otra. Por supuesto, el examen muestra el valor educativo esencial de la atención y hace que no nos limitemos a convertir la actividad (profesional o educativa) en una sucesión imparable de acontecimientos. Pero la afirmación de la importancia del examen va más allá de crear espacios de detenimiento que sean un momento de conexión con el propio espacio de libertad (BADARACCO, 2002). La afirmación de la importancia del examen es la afirmación de la importancia de estar plenamente presente para poder posibilitar tanto la acción transformadora como el ejercicio del liderazgo (SENGE ET AL., 2004). El examen es una práctica por la cual el hombre se halla autopresente a sus propias acciones. ${ }^{22}$ Este es, en último término, el reto que se plantea a las JBS: en qué medida suscitamos la capacidad, en los futuros profesionales de la gestión, de estar autopresentes en sus propias acciones. Ni que decir tiene que ello también interpela a las JBS sobre la presión de los planes de estudios, a los que en ocasiones convendría recordar que en nuestro camino por la vida no el mucho saber harta y satisface al ánima (EE, 2).

Si el examen apunta a desarrollar la capacidad de estar autopresentes en las propias acciones, siguiendo los EE hay dos tipos de orientaciones prácticas para introducirse en esta capacidad que es recomendable considerar, en especial por su impacto en la estructuración de todo liderazgo.

En primer lugar, en lo referente al examen, convendría fijarse en la tradicional división sobre el objeto del examen: pensamientos, palabras y obras. Porque, de nuevo, lo que aquí está en juego es la profundización en el camino de la libertad, y no un mero esfuerzo analítico. En lo relativo a los pensamientos, es fundamental recordar que San Ignacio no se refiere simplemente a enunciados mentales, sino que al hablar de pensamientos se refiere a los dinamismos y a las mociones que mueven a una determinada acción. Se trata de situarnos, de nuevo, en una mayor lucidez con respecto a lo que "queremos y elegimos", y dar nombre a las fuerzas pulsionales presentes en nosotros y que tan a menudo enmascaran la libertad y convierten en razones lo que son meras racionalizaciones. El otro componente es la asunción de la dimensión relacional de la acción y, por tanto, del acto de

\footnotetext{
22 ARZUBialde, 91.
} 
libertad. De ahí la importancia de atender a las palabras y a las obras: al fin y al cabo, la verificación del propósito -al que hemos dado tanta importancia- no se produce en su enunciación, sino en las palabras y las obras.

En segundo lugar, el examen nos dispone para el re-conocimiento de la posibilidad y la realidad del mal como un componente del camino hacia la libertad. FESSARD ha puesto de relieve que, sin una mirada interna hacia la realidad del no-ser (hacia todo lo que niega dentro y fuera de nosotros mismos lo que queremos ser), no podremos re-conocer nuestro camino en la vida: La oposición entre el Bien y el Mal con la que nos encontramos en todas las encrucijadas refleja la ambigüedad de nuestra naturaleza. ${ }^{23}$ Como ya bien sabemos, en los EE no se presta atención sólo al mal que hay en mí, sino que se trata también de captar la estructura del mal en la que me hallo inscrito. Esta atención a la posibilidad y a la realidad del mal creo que también forma parte, en sí misma, de lo que, siguiendo a KOLVENBACH, hemos denominado "crítica a la cultura", que aquí debería convertirse en crítica a la cultura dominante en el mundo de las empresas. En efecto, la pregunta acerca del mal y el sufrimiento que se genera a través de la acción que busca eficiencia y resultados es el auténtico tabú, la pregunta censurada en el mundo de las empresas, que vive preso del mito indiscutible del éxito y los resultados como principio último de legitimación. Si tomamos aquí -sólo como metáfora- la famosa afirmación de Schumpeter acerca del capitalismo como "creación destructiva", no nos costará demasiado concluir que, en la práctica, esta afirmación desemboca a menudo en que el valor supremo de la creación (de riqueza, de tecnología, etc.) legitima por si misma la eventual destrucción que pueda llevar aparejada, aunque le acompañen lo que BAUMAN (2004) ha denominado vidas desperdiciadas.

Por tanto, cuando afirmamos que no se accede a la libertad con respecto a lo que yo quiero y elijo sin conciencia de la posibilidad y la realidad del mal, lo que estamos afirmando, de acuerdo con los $\mathrm{EE}$, es la importancia de desarrollar un pensamiento sensible y sensibilizado (ARZUBIALDE, 1991), eso es, atento tanto al contexto como a las consecuencias. ${ }^{24}$ ¿Cómo se puede ir alcanzando progresivamente este pensamiento sensible y sensibilizado? Antes hemos dicho que es en la capacidad de estar autopresente en las propias acciones y decisiones mediante la atención lúcida

\footnotetext{
${ }^{23}$ FeSSARD, 71.

${ }^{24}$ Ello obligaría a preguntarse, repitámoslo, si el pensamiento que se propone sobre la empresa en las JBS es un pensamiento "autista", encerrado en sí mismo, que reproduce el discurso convencional y dominante sobre la empresa y los negocios, o bien es un pensamiento sensible y sensibilizado, que lleva críticamente más allá de sí mismo.
} 
a nuestras mociones, nuestras palabras y nuestras obras. Pero, más adelante, san Ignacio nos da las referencias de dónde se lleva a cabo esto: Mirando de año en año o de tiempo en tiempo, para lo cual aprovechan tres cosas: la primera, mirar el lugar y la casa donde he habitado; la segunda, la conversación que he tenido con otros; la tercera, el oficio en que vivido (EE, 56). En otras palabras: consiste en fijarme en mi trayectoria, en mis contextos, en mis relaciones y en mis actividades profesionales. Y, llegados a este punto, procediendo así, la educación en una JBS no puede dejar de plantear también la meditación sobre el infierno (sin perder el tiempo en discutir las adherencias producto de siglos de imágenes distorsionadoras). Porque toda persona que quiera involucrarse en el mundo de la empresa tiene que plantearse claramente que es perfectamente posible ly a veces absolutamente real) perderse totalmente como persona y como ser humano en el ejercicio de la profesión; o hacerles perder a los demás su propia humanidad. Y que hoy este perderse humanamente es perfectamente compatible con la consecución de lo que la cultura empresarial dominante denomina éxito.

Así pues, el examen individual y general nos interpela en la medida en que nos hace caer en la cuenta de que no es posible desarrollar la capacidad de liderazgo sin desarrollar la capacidad de autopresencia en la acción, un pensamiento sensible y sensibilizado, y la atención a la posibilidad y la realidad del mal (que puede llegar incluso a la pérdida de uno mismo como persona).

\section{4. "Poner delante de mí un rey humano..." (EE 9/-98)}

La meditación de la llamada del rey temporal ${ }^{25}$ nos confronta directamente con la gran pregunta omitida en muchas aproximaciones al liderazgo: los seguidores. Y ello referido a tres dimensiones: no hay liderazgo sin seguidores; no hay líderes que en algún momento no hayan sido seguidores, y no hay liderazgo sin un seguimiento y/o una relación a una causa. Pero la meditación del rey temporal pone de relieve, por encima de todo, un punto fundamental: convertirse en un líder es un resultado y no un mero objetivo; es más: no es un objetivo por sí mismo. Es el resultado de elegir causas que tengan sentido, que generen relaciones, y que nos hagan crecer humanamente... si es que hablamos de líderes que sean hombres y

${ }^{25}$ San Ignacio propone: "El llamamiento del rey temporal ayuda a contemplar la vida del rey eternal" (EE 91) para que el que hace los Ejercicios sea "presto y diligente para cumplir" la voluntad de Dios (el rey eternal). 
mujeres para los demás y con los demás." ${ }^{26}$ San lgnacio recomienda entrar en los Ejercicios con grande ánimo y liberalidad (EE, 5): lo mismo vale para el liderazgo, porque el buen liderazgo -al menos desde una perspectiva ignaciana- no se centra en el líder sino en la causa, y en la disposición a comprometerse con ella y a involucrarse en ella. Y si el liderazgo se aprende en el seguimiento, entonces el reto educativo central para una JBS es qué causas y personas se proponen como referencia a los participantes en sus programas de formación.

Si hablamos de la llamada del rey temporal es porque dicha llamada está relacionada con el propósito. El propósito no se centra en el "yo" sino en "servir". Podríamos decir que no se trata tanto de afirmar Yo sirvo a, sino más bien yo Sirvo a: la mayúscula no debe estar en el Yo sino en el Sirvo ${ }^{27}$. Dicho en otras palabras: el quién, el qué y el cómo son inseparables, y ninguno de los tres se justifica por sí mismo al margen de los otros dos. En los $\mathrm{EE}$, san Ignacio pone esta meditación como prólogo y fundamento de la contemplación de toda la vida de Jesús (que es donde detenemos el itinerario que hemos seguido, de acuerdo con nuestra reconstrucción de las "anotaciones" de los EE). Pero podríamos decir también que antropológicamente esta meditación es el prólogo de toda una comprensión del liderazgo que pone el acento en la causa y el propósito, y no directamente y prioritariamente en el líder (o que no comprende ni valora el líder al margen de la causa y el propósito).

En esta meditación emerge, de nuevo, la importancia de un pensamiento sensible y sensibilizado. No hay seguimiento ni liderazgo sin aprender a mirar y a escuchar; sin educar la mirada y la escucha. Educación de la mirada: San Ignacio invita a mirar la realidad del mundo y de la historia como punto de partida de la meditación; una mirada, no obstante, que no es meramente analítica o descriptiva, sino que se orienta a tomar posición, a incidir en el mundo y a transformarlo. Volvemos, pues, al reto del des-centramiento, de saber ver la realidad del mundo y de la historia desde ella misma y no desde mis intereses (lo que se acentuará en la siguiente meditación sobre la Encarnación). En segundo lugar, educación de la escucha: es preciso no ser sordo (EE, 91) a la llamada. El centro no es el rey temporal, sino la llamada a la que él nos convoca. Esta receptividad básica es disponibilidad a dar respuesta a la realidad del mundo para transformarlo, al servicio de un proyecto que tiene valor por sí mismo, un proyecto al que somos convocados: de nuevo, una visión compleja del liderazgo. No es de extrañar, pues, que la mane-

${ }^{26}$ KolveNBACH, Roma y México, 2007.

27 Véanse los planteamientos de A. DelBECQ (2011). 
ra en que san Ignacio vertebra la respuesta a la llamada del rey temporal sea el código ético medieval de la caballería andante. ${ }^{28}$ La llamada a la excelencia, el compromiso y la disponibilidad se formula desde el horizonte hermenéutico de su época y desde el ideal humano propio de las categorías del tardomedievo. ${ }^{29}$ Lo que hoy nos dice la meditación sobre la llamada del rey temporal es que "no hay invitación al liderazgo ni educación del liderazgo sin proponer una llamada a la excelencia, al compromiso y a la disponibilidad desde el horizonte hermenéutico de nuestra época, y desde el ideal humano propio de nuestras categorías". Y que tenemos que hacerlo no a base de discursos (o no sólo), sino proponiendo modelos personificados de realización de lo que hoy sería el código ético profesional.

En otras palabras: en las JBS, los grandes retos y las causas de la humanidad y de diferentes países ¿̇son propuestas y expuestas, y no sólo de una forma descriptiva e informativa? ¿ Se pone a los estudiantes en contacto, directa o indirectamente, con personas (no necesariamente famosas) que hayan encarnado estas grandes causas? Porque nuestra identidad personal y profesional se construye a través de nuestras experiencias de liderazgo pero, sobre todo, a través de las relaciones que establecemos con nuestros referentes. "Y la educación consiste, en último término, en proponer referentes". De hecho, las prácticas educativas de las escuelas de negocios comportan constantemente la presentación y la propuesta-deliberada, tácita o inconsciente-de referentes personales y organizativos, a través de casos, ponentes invitados, ejemplos seleccionados en las prácticas facilitadas, etc. Llegados a este punto, en la línea de la meditación sobre la llamada del rey temporal, conviene no olvidar lo siguiente:

La identificación [...] se define como un proceso psicológico mediante el cual un sujeto asimila un aspecto, una propiedad, un atributo de otro y se transforma, total o parcialmente, sobre el modelo de éste.

De hecho, la personalidad se constituye y se diferencia mediante una serie de identificaciones, en unos procesos que implican los niveles más profundos de la afectividad, gracias a los cuales nace, se estructura y se configura el propio yo. Es, por tanto, mucho más que un aprendizaje, como proceso que concierne tan sólo a la adquisición de unas capacidades determinadas. [... Es, tal como ha formulado H. KOHUT, una internalización transmutadora que logra una nueva estructuración del sujeto. ${ }^{30}$

\footnotetext{
${ }^{28}$ ArZubialde, 222.

${ }^{29}$ Arzubialde, 232.

30 Domínguez, 34. Subrayados del original.
} 
¿Qué referentes proponemos, pues, en las JBS? ¿Cómo acompañamos a los estudiantes en la elaboración del impacto que tendrán en ellos estos referentes? ¿Podemos pretender educar para el liderazgo sin haber educado experiencialmente el seguimiento y el compromiso?

5.5. "Cómo las tres personas divinas miraban toda la planicia o redondez de todo el mundo llena de hombres..." (EE I0I-109)

No existe actualmente ninguna escuela de negocios donde no se hable de la globalización. La pregunta es cómo se habla de ella y desde qué clave de comprensión. Porque de lo que se trata es de contemplar la globalización y la globalidad, y no simplemente aprender y saber más de ellas. Acaso la meditación sobre la encarnación sea una de las primeras aproximaciones que nos dan una clave de lectura (GONZÁlEz FAUS Y MoLLÁ, 1997) para comprender lo que hoy denominamos globalización: un enfoque que es un auténtico marco para realizar una aproximación a la globalización inspirada en los EE. Veamos la sucesión de enunciados que trazan esta aproximación:

- Mirar toda la planicia o redondez de todo el mundo lleno de hombres (EE, 102)

- Ver el lugar, aquí será ver la grande capacidad y redondez del mundo, en el cual están tantas y tan diversas gentes (EE, 103)

- Es ver las personas, las unas y las otras; y primero, las de la haz de la tierra, en tanta diversidad, así en trajes como en gestos; unos blancos y otros negros, unos en paz y otros en guerra, unos llorando y otros riendo, unos sanos, otros enfermos, unos naciendo y otros muriendo, etc. (EE, 106)

- Oír lo que hablan las personas sobre la haz de la tierra, es a saber, como hablan unos con otros, como juran y blasfeman, etc. (EE, 107)

- Después de mirar lo qué hacen las personas sobre la haz de la tierra, así como herir, matar, ir al infierno, etc. $(\mathrm{EE}, 108)$

De nuevo nos hallamos ante una aproximación que nos viene a decir que no podemos pensar la globalización más que a través de un pensamiento sensible y sensibilizado (ver, mirar y escuchar); ni podemos aproximarnos a la misma si no es a través de atender a lo que la diversidad de personas, en la diversidad de situaciones y contextos, dicen y hacen. Se trata de una aproximación inclusiva (MÀrIA y LozANO, 2010), en vez de una aproximación selectiva y hegemónica. 
Una aproximación selectiva a la globalización es aquella que sólo atiende a aquellos aspectos, realidades y procesos que encajan con las propias prioridades e intereses (o con la propia agenda económica, política o intelectual), y no toma en consideración todo lo que no encaja en ellas. Una aproximación hegemónica a la globalización es la que impone sus propias prioridades e intereses, y excluye todas las voces, los grupos y las realidades sociales que no encajan o, simplemente, que se oponen a ella. Una aproximación inclusiva es aquella que, al menos como actitud intelectual, operativa y ética, se esfuerza por tener en cuenta la diversidad de voces, conflictos e intereses a la hora de analizar y entender cualquier fenómeno vinculado a la globalización, y convierte esta voluntad de totalidad inclusiva en la clave de su estructura. La interpelación que desde la meditación sobre la encarnación se hace a las escuelas de negocios -y, por supuesto, a las JBS- es si han divulgado y legitimado una comprensión de la globalización selectiva, hegemónica o inclusiva, y consiguientemente si, más allá de una mera incorporación de la RSE - la ética empresarial a los currículos, educan para el ejercicio de una ciudadanía responsable (MARGENAT, 2008; LOZANO, 2009).

En último término, la comprensión de la globalización se corresponde directamente con la comprensión del liderazgo que se propone. Porque la meditación sobre la Encarnación va más allá del desarrollo de un pensamiento sensible y sensibilizado para una globalización inclusiva. Conduce directamente a la interpelación por "bajar" a la realidad del mundo e involucrarse en él para transformarlo. Este proceso no excluye el liderazgo (más bien lo incluye y lo necesita), pero es una aproximación que no pone el acento en el "ascenso" al liderazgo, sino en el "descenso" a la realidad histórica que le ha tocado vivir a cada cual (ESTRADA, 1999). Nos encontramos, pues, de nuevo con una visión del liderazgo como relación, y no como posición. En otras palabras, si anteriormente hemos recordado la afirmación de KOLVENBACH según la cual "en la educación jesuita, la regla para medir la calidad de una universidad es la calidad humana que logra el estudiante", ahora podemos añadir que su complemento es la pregunta sobre cómo los estudiantes "bajan" a la realidad (jlas realidades!) de la tierra. ¿2Para servir a quién? ¿̇Es una interpelación que reciben a través del currículo básico de los programas de formación, o como máximo a través de actividades complementarias y periféricas? Porque se trata de incidir allí donde se construyen propiamente la carrera profesional y la identidad personal.

En cierto sentido, podríamos decir que la interpelación que la meditación sobre la encarnación comporta para nuestra comprensión del liderazgo nos devuelve directamente a la Gaudium et Spes: ¿Llos gozos y las esperanzas, las tristezas y las angustias de los hombres de nuestro tiempo, sobre todo de los pobres y de 
cuantos sufren, son a la vez gozos y esperanzas, tristezas y angustias de... ${ }^{31}$ los estudiantes de una JBS? ¿iNo debe éste ser un componente clave en la comprensión del liderazgo que se ofrece desde una JBS?

\section{Conclusión}

En estas páginas he querido plantear cómo una lectura de los EE puede ser, a la vez, una instancia crítica y un punto de apoyo para una indagación sobre la aproximación al liderazgo que debería hacerse en una JBS. Entre otras razones, porque se centra en los procesos de transformación personal (LEFRANK, 1999), en el vínculo entre autoconocimiento y liderazgo (LOWNEY, 2010) y en la prioridad dada al "servir" (KolveNBACH).

En primer lugar, he querido poner de relieve que una aproximación al liderazgo no puede reducirse a centrarse en los líderes, sino que necesita articularse en la relación entre cuatro elementos: líder, seguidores, proyecto y medios. Y, más concretamente, debe elaborar:

1. No sólo las competencias y habilidades de los líderes, sino también su calidad humana.

2. No sólo las características y la implicación de los seguidores, sino también sus relaciones, sus compromisos y sus valores.

3. No sólo la formulación de los objetivos del proyecto, sino también su coherencia ética.

4. No sólo el éxito al lograr los objetivos del proyecto, sino también los medios utilizados para alcanzarlos.

En segundo lugar, he propuesto una relectura de las anotaciones 18 y 19 de los $\mathrm{EE}$, especialmente en lo referente a la recomendación ignaciana de dar los ejercicios de la primera semana -y algunos más-a dos tipos diferentes de persona: las muy ocupadas, y las personas más rudas o sin letras. El primer perfil, evidentemente, es muy común entre los asistentes a una escuela de negocios. En la actualidad, el segundo perfil podría reformularse diciendo que, en un contexto plural y posmo-

${ }^{31}$ Constitución pastoral Gaudium et Spes sobre la Iglesia en el mundo de hoy, Concilio Vaticano II (1965) n. 1. 
derno, una persona puede recibir una gran cantidad de formación especializada y que ello sea compatible con una total ausencia de atención y dedicación a las dimensiones donde se juega la construcción del sentido de la vida, que a menudo quedan excluídas del marco de referencia vital. Por esta razón, he considerado - a partir de la recomendación ignaciana- que puede resultar útil una exploración en clave antropológica de algunos elementos de la primera y la segunda semanas de los EE, desde el supuesto de que podrían utilizarse como una heurística de lo que se propone en una escuela de negocios.

Finalmente, en tercer lugar, como resultado de esta exploración, he propuesto un marco de referencia sobre los criterios que debería tener en cuenta transversalmente en toda su propuesta educativa una JBS atenta a lo que podría ser una aproximación al liderazgo de inspiración ignaciana. Algunos de estos criterios son:

- No hay liderazgo sin desarrollar ni cuidar la receptividad con respecto a las proposiciones de los demás, sin el esfuerzo de comprenderlas y sin la disposición a responder a ellas -en el sentido que sea- con libertad. (Del prosupuesto, EE 22).

- No es posible hacer ninguna propuesta sobre el liderazgo sin confrontar críticamente a los estudiantes con la explicitación de su propósito profesional y vital, sin trabajar en la educación del deseo y sin activar la capacidad de indiferencia, precisamente como base para un compromiso apasionado. (Del principio y fundamento, EE 23).

- No es posible fortalecer la capacidad de liderazgo sin desarrollar la capacidad de autopresencia en la acción, un pensamiento sensible y sensibilizado, y la atención a la posibilidad y a la realidad del mal, sin descartar poder llegar hasta la pérdida de uno mismo como persona. (Del examen general e individual, EE 24-43).

- No es posible trabajar personalmente el liderazgo sin tomar en consideración y dar la máxima importancia a los referentes concretos y a las grandes causas que proponemos a los estudiantes, así como al acompañamiento que realizamos y el apoyo que damos a la elaboración personal del impacto que tienen en ellos dichos referentes y causas. (De la llamada del rey temporal, EE 91-98).

- La interpelación por el liderazgo es indisociable de la interpelación por "bajar" a la realidad del mundo e involucrarse en él para transformarla. Este proceso no excluye que se necesiten líderes (más bien lo incluye porque 
son imprescindibles), pero es una aproximación que no pone el acento en el "ascenso" a la posición de liderazgo, sino en el "descenso" -dando prioridad a la pregunta por el servicio- a la realidad histórica que le ha tocado vivir a cada cual. (De la meditación sobre la Encarnación, EE 101-109).

Este marco puede ser útil para la indagación de lo que es más importante, que no es el propio marco sino cómo esta concepción crítica del liderazgo se disemina concretamente a través de todas las prácticas educativas y las actividades docentes. Porque, al final, en una JBS todo ello debe traducirse en la realización práctica de ejercicios para preparar y disponer el ánima para quitar de sí todas las afecciones desordenadas $(E E, 1)$. Pero, incluso en el caso de que lo que me he propuesto llevar a cabo hubiera resultado un intento fallido, permanece abierta y viva una pregunta: ¿̇hay algo que diferencie y distinga la aproximación al liderazgo que se realiza desde una JBS?

\section{Bibliografía}

AGÚNDEZ, M. (2008) "El paradigma univesitario Ledesma-Kolvenbach": Revista de Fomento Social, 63, 603-631.

Arzubialde, S. (1991) Ejercicios espirituales de San Ignacio. Historia y análisis, Santander, Sal Terrae.

Badaracco, J. (1998) "The Discipline of Building Character": Harvard Business Review (marzo-abril), 115-124.

Badaracco, J. (2001) "We Don'† Need Another Hero": Harvard Business Review (septiembre), 121-126.

BADARACCO, J. (2002) Leading Quietly, Boston, Harvard University.

BARBeR, B. R. (1998) A Place for Us, Nueva York, Hill and Wang.

BarRATt, R. y KorAC-KaKABADSE, N. (2002) "Developing reflexive corporate leadership": Corporate Governance, 2(3), 32-36.

Bauman, Z. (2000) Liquid Modernity, Cambridge, Polity.

Bauman, Z. (2003) Liquid Love: On the frailty of human bonds, Cambridge, Polity. 
Bauman, Z. (2004) Wasted Lives, Cambridge, Polity.

BeauCHemin, J. (2006) "Grandeur et misère de l'idée de responsabilité sociale", en: GAGNON, É. y SAILANT, F. (2006) De la responsabilité. Ethique et politique, Montréal, Liber, 87-103.

BECK, U. (1992) Risk Society: Towards a new modernity, Londres, Sage.

BECK, U. (2000) What is Globalization?, Cambridge, Polity.

Benedicto XVI (2009) Caritas in veritate.

BenNIIS, W. G. y O'Toole, J. (2005) "How Business Schools Lost Their Way?": Harvard Business Review (mayo), 96-104.

Carroll, A. B. (1999) "Corporate Social Responsibility. Evolution of a definitional construct": Business \& Society, 38(3), 268-295.

Carroll, A. B. y BuchHoltz, A. K. (2003) Business \& Society. Ethics and Stakeholder Management, Mason, South-Western.

Castells, M. (1996) The Rise of the Network Society, Oxford, Blackwell.

Castiñeira, À. y Lozano, J. M. (2009) El valor de los liderazgos, Barcelona, ESADE.

CIULLA, J. B. (2005a) "The state of leadership ethics and the work that lies before us": Business Ethics: A European Review, 14(4), 323-335.

CIULLA, J. B. (2005b) "Integrating leadership with ethics: Is good leadership contrary to human nature?", en DOH, J. P. y STUMPF, S. A. (2005) Handbook of Responsible Leadership and Governance in Global Business, Cheltenham, Edward Elgar, 159-178.

CoRBí, M. (1998) El camí interior. Més enllà de les formes religioses, Barcelona, Viena.

CORBí, M. (2007) Hacia una espiritualidad laica. Sin creencias, sin religiones, sin dioses, Barcelona, Herder.

CoveY, S. R. (1992) Principle-Centred Leadership, Londres, Simon and Schuster.

DeCloux, S. (2001) "El más está en ti": Manresa, 73, 175-185. 
DelbeCQ, A. L. "Escuelas de negocio en la educación jesuita. Cuatro reflexiones. http://itemsweb.esade.edu/wi/documentos/iesuitas2.pdf (última consulta: 20.05.2011)

DeLISLE, S. y RINFRET, N. (2006) "Le servant leadership: une approche du leadership inspirée par le christianisme et l'éthique", en Chaire La Capitale en leadership dans le secteur publique (noviembre).

Domínguez, C. (2001) "El sujeto que ha de elegir hoy, visto desde la psicología (I)". Manresa, 73, 145-160.

DOMínGUez, C. (2008) "'Quien quisiere venir conmigo...' (EE 95). La configuración psicosocial de la identidad": Manresa, 80, 33-46.

DonNelly. M. A. (2010) "The Spiritual Exercices: A paradigm for a reflection on good teaching": Journal of Jesuit Business Education, 1(1), 51-76.

EISENBACH, R.; WATSON, K.; PILLAI, R. (1999) "Transformational leadership in the context of organizational change": Journal of Organizational Change, 12(2), 80-88.

EstradA, J. A. (1999) "Conocimiento interno del mundo para que más le ame y le sirva": Manresa, 71, 63-80.

ETXEBERRIA, X. (2008) "Fides-I: cultivar la dimensión trascendente": Revista de Fomento Social, 63, 691-714.

Etzıonl, A. (2001) The Road to the Good Society, Nueva York, Basic Books.

Fessard, G. (2010) La dialéctica de los Ejercicios espirituales de San Ignacio de Loyola. Santander, Sal Terrae.

FLORENSA, A. (2008) "Humanitas: la persona en el centro del proceso de formación": Revista de Fomento Social 63, 671-690.

Freeman, R. E. (1999) "Divergent stakeholder theory": Academy of Management Review, 24(2), 233-236

GARCíA, J. A. (2000) "'Salvar el ánima' [23]. El sujeto moderno entre el aferramiento y el éxtasis", Manresa, 72, 29-40.

GIDDENS, A. (2000) Runaway World. Londres, Profile. 
GOFFEE, R. y JONES, G. (2006) "The art of followership": European Business Forum, $25,22-26$.

GOMÁ, J. (2003) Imitación y experiencia, Valencia, Pre-textos.

GOMÁ, J. (2009) Ejemplaridad pública, Madrid, Taurus.

Gómez Caffarena, J. (1997) "Principio y fundamento para agnósticos": Manresa, $69,333-347$.

GonzÁlez FAUs, J. I. y MolL̀̀, D. (1997) Fem redempció del gènere humà, Barcelona, Cristianisme i Justícia.

Greenleaf, R. K. (1977) The Servant as Leader, Nueva York, Paulist.

GrouPE DE LISBONNE (1997) Limites à la competitivité, París, Labor.

GuerRero, J. A. (1998) "El principio y fundamento de los Ejercicios espirituales como filosofía de vida y estilo político": Manresa, 70, 179-195.

HaRLE, T. (2005) "Serenity, Courage and Wisdom: Changing competencies for leadership": Business Ethics: A European Review, 14(4), 348-358.

Helfetz, R. A. (1994) Leadership without Easy Answers, Cambridge (EE.UU.), Harvard University.

Held, D.; y MCGrew, A. (2007) Globalization / Anti-Globalization, Cambridge, Polity.

HORTAL, A. (2008) "Utilitas: la dimension práctica de la formación universitaria". Revista de Fomento Social, 63, 633-650.

HORNER, M. (1997) "Leadership Theory: Past, present and future". Team Performance Management, 3(4), 270-287.

IGLESIAS, I. (1998) "¿Es la hora de los Ejercicios 'leves'?": Manresa, 70, 49-60.

IgnaCiO de Loyola (21990) Ejercicios Espirituales (edición de C. de DaLmASES), Santander, Sal Terrae.

JeNSEN, M. (2007) A New Model of Leadership, Barcelona, ESADE.

JONAS, H. (1992) Le Principe responsabilité, París, Cerf. 
Kark, R. y VAN DIJK, D. (2007) "Motivation to Lead, Motivation to Follow: The role of the self-regulatory focus in leadership processes": Academy of Management Review, 22(2), 500-528.

Kegan, R. y Lahey, L. L. (2001) How the Way We Talk Can Change the Way We Work, San Francisco, Jossey Bass.

Kegan, R. y LAHEY, L. L. (2009) Immunity to Change, Boston, Harvard Business.

Khurana, R. (2007) From Higher Aims to Hired Hands: The social transformation of American business schools and the unfulfilled promise of management as a profession, Princeton, Princeton University.

KolvenBaCH, P.-H. (2008) Discursos universitarios, Madrid, UNIJES.

Lefrank, A. (1999) "Los Ejercicios como proceso de transformación": Manresa, $71,121-134$.

LIBANIO, J. B. (1997) "Principio y fundamento desde una perspectiva ecológica": Manresa, 69, 215-226.

LIPOVETSKY, G. (1992) Le crépuscle du devoir. L'éthique indolore des nouveaux temps démocratiques, París, Gallimard.

LOWNEY, C. (2004) Heroic Leadership, Chicago, Loyola.

LOWNEY, C. (2010) "The Competitive Advantage of Jesuit Business Schools": Journal of Jesuit Business Education, 1 (1), 37-50.

LosAdA, C., MARTELL, J. y LozANo, J. M. (2011) "Responsible business education: not a question of curriculum but a raison d'etre for business schools" (en prensa).

LozAno, J. M. (1999) Ética y empresa, Madrid, Trotta.

LozANO, J. M. (2009) La empresa ciudadana como empresa responsable y sostenible, Madrid, Trotta.

LYOTARD, J.-F. (1984) La condición posmoderna, Madrid, Cátedra.

MAAK, T. y PLESS, N. (2006) "Responsible leadership. A relational approach", en MAAK, T. y PLESS, N. (2006) Responsible Leadership, Londres, Routledge, 34-53. 
MaclntYRe, A. (1981) After Virtue, Notre Dame, University of Notre Dame.

MARGENAT, J. M. (2008) "lustitia: educar para una ciudadanía responsable": Revista de Fomento Social, 63, 651-669.

MÀrIA, J. F. y LOZANO, J. M. (2010) "Responsible leaders for inclusive globalization": Journal of Business Ethics, 93, 93-111.

MeLLONI, X. (2009) El desig essencial, Barcelona, Fragmenta.

MiRAlles, J. (2008) "Fides-II: creyentes y no creyentes compartiendo una misma misión": Revista de Fomento Social, 63, 715-739.

OlenIACZ, T. (2001) "La acomodación de los Ejercicios espirituales de San Ignacio según el libro de los Ejercicios y los directorios", Manresa, 73, 95-106.

Petrella, R. (1997) Le bien commun, París, Labor.

PruZAN, P. y MiKKelSen, K. P. (2007) Leading with Wisdom, Sheffield, Greenleaf.

RIBERA, R. (2008) "Empresa y calidad humana": Revista ICADE, 75, 267-289.

Quatro, S. A., Waldman, D. A. y Galvin, B. M. (2007) "Developing Holistic Leaders: Four domains for leadership development and practice": Human Resource Management Review, 17, 427-441.

SARROS, J. C. y SANTORA, J. C. (2001) "The transformational-transactional leadership model in practice": Leadership \& Organization Development Journal, 22(8), 383-393.

Sarros, J. C. y CoOper, B. K. (2006) "Building Character: A leadership essential": Journal of Business and Psychology, 21(1), 1-22.

Sauquet, A. (2008) Pensar el liderazgo. Organizar y liderar: el qué, el cómo y el cuándo, Barcelona, ESADE.

ScHÖN, D. A. (1987) Educating the Reflective Practitioner, San Francisco, Jossey-Bass.

SEGUNDO, J. L. (1996) "¿Una primera semana sin cristología?": Manresa, 68, 233-247. 
Senge, P., Scharmer, C. O., Jawoerski, J. y Flowers, B. S. (2004) Presence, Nueva York, Double Day.

Sennett, R. (1998) The Corrosion of Character: The Personal Consequences of Work in the New Capitalism, Nueva York, W. W. Norton \& Co.

Solomon, R. C. (2002) Spirituality for the Skeptic, Oxford, Oxford University Press.

SPEARS, L. (2002) "Tracing the past, present and future of servant-leadership", en Spears, L. C. y LAWrence, M. (2002) Focus on Leadership, Nueva York, John Wiley \& Sons, $1-16$.

SPITZER, R. J (2010) "The distinctiveness of Jesuit Schools": Journal of Jesuit Business Education, 1(1), 1-16.

TAYLOR, C. (1993) El multiculturalismo y la "política del reconocimiento", México, FCE, 43-108.

TOURAINE, A. (1997) ¿2Podremos vivir juntos? Iguales y diferentes, Madrid, PPC.

TugendHAT, E. (2004) Egocentricidad y mística. Un estudio antropológico, Barcelona, Gedisa.

VALADIER, P. (1997) L'anarchie des valeurs, París, Albin Michel.

VAтTIMO, G. (1985) El fin de la modernidad. Nihilismo y hermenéutica en la cultura posmoderna, Barcelona, Gedisa, 1986.

Vattimo, G. y Rovamı, P. A. (eds.) (1983) Il pensiero debole, Milán, Feltrinelli.

WADDOCK, S. (2001) "Integrity and Mindfulness. Foundations of corporate citizenship": Journal of Corporate Citizenship, 1, 25-37.

WYADDOCK, S. (2007) "Leadership Integrity in a Fractured Knowledge World": Academy of Management Learning \& Education, 62(4), 543-557.

WEYICK, K. E. (1995) Sensemaking in Organizations, Londres, Sage.

WINDYSOR, D. (2001) "Corporate Citizenship. Evolution and interpretation", en ANDRIOF, J. y MCINTOSH, M. (2001) Perspectives on Corporate Citizenship, Sheffield, Greenleaf, 38-52. 